\title{
Quando e Como o Homem Começou a "Ver" os Átomos!
}

\author{
(When and How Mankind Started to See Atoms!) \\ Caio Mário Castro de Castilho \\ Grupo de Física de Superfícies e Materiais \\ Instituto de Física, Universidade Federal da Bahia \\ Campus Universitário da Federação, 40210-340 Salvador, Bahia, Brasil
}

Recebido em 23 de maio, 2003. Aceito em 8 de setembro, 2003.

\begin{abstract}
O conceito de átomo é anterior a qualquer tentativa de compreender a natureza a partir do experimento. Não obstante, o conceito de átomo, formulado inicialmente pelos gregos e posteriormente apresentado a partir da interpretação de experimentos, só vem a se estabelecer completamente na linguagem científica ao final do século dezenove e início do século vinte. Inicialmente tida como tarefa impossível, a obtenção de imagens capazes de evidenciar átomos individualmente foi conseguida na metade do século recém-findo mediante a técnica de Microscopia Iônica. Este trabalho apresenta uma breve noção do desenvolvimento da idéias sobre os átomos e descreve os principais passos que levaram à obtenção das primeiras imagens de átomos individuais por E. W. Muller e colaboradores, na primeira metade da década de 50, no século XX.

The concept of atom is older than any tentative of trying to understand nature from an experimental approach. Nevertheless, the concept of atoms, as initially conceived by the Greeks and later on presented from experiments and its interpretation, only become well established on the scientific jargon by the end of the nineteen century and beginning of the twentieth. Initially considered as an impossible task, images able in identifying individual atoms were, for the first time, obtainable by the middle of last century through the Field Ion Microscopy technique. This work presents a brief summary on how developed the ideas about atoms and describes the main steps which led to the first images of individual atoms by E. W. Müller and collaborators, during the first half of the fifties of the twentieth century.
\end{abstract}

Em 2001 completaram-se 50 anos da publicação do primeiro artigo, de autoria de Erwin W. Müller, sobre o Microscópio Iônico de Campo (Field Ion Microscope - FIM), o equipamento que possibilitou ao homem, pela primeira vez, "ver" átomos individualmente, isto é, distinguir entre as posições de dois átomos vizinhos - um feito marcante na Física do século recém-findo.

É hoje consensual que a idéia de átomo remonta à civilização grega. A própria palavra átomo vem do grego e é composta de $\alpha^{\prime}$, que corresponde a uma negativa, juntamente com $\tau \varepsilon^{\prime} \mu \varepsilon \iota v$, que diz respeito a cortar, partir, dividir. Demócrito (século quinto AC) concebia os átomos como as menores partículas da matéria, ainda que não os imaginasse como necessariamente pequenos (no conceito de pequeno que temos hoje). A composição da matéria, na visão de Empédocles (490 - 430 AC), resultava de quatro elementos indestrutíveis (fogo, ar, água e terra) - uma visão ainda hoje assim apresentada por muitos místicos. Estes elementos, se uniam mediante ou se separavam como conseqüência, de duas forças divinas: amor e discórdia. Epicuro (341 270 AC), por sua vez, afirmava que os átomos não podiam ser divididos em partes menores por nenhum meio, ainda que eles possuíssem estrutura. Lucrécio (romano, 98 - 55 $\mathrm{AC})$ concebia os átomos como infinitos em número e restritos nas suas variedades e seriam, juntamente com o espaço vazio, as únicas entidades eternas e imutáveis das quais o mundo físico era constituído. A visão oposta, no entanto, ou seja, a de continuidade e divisibilidade sempre possível, possuía também defensores. Anaxágoras (500 - 428 AC) e Aristóteles (384 - 322 AC) estavam entre estes. O grande sucesso de Aristóteles, em vários outros campos, provavelmente contribuiu para que a visão atomística não prosperasse, pelo menos até o século dezessete. A concepção da matéria como constituída por átomos, inicialmente resultado apenas de uma construção especulativa, essencialmente não se altera no período que vai da Grécia Antiga até o final do século dezoito e início do século dezenove.

Os trabalhos de Lavoisier (1743 - 1794), Dalton (1766 - 1844), Avogadro (1776 - 1856), Berzelius (1779 - 1848), Mendeleev (1834 - 1907), entre outros, contribuíram decisivamente para o estabelecimento dos conceitos de átomo e de molécula mas, a despeito disto, a situação estava longe de uma solução mesmo em 1860 durante o congresso de Química realizado em Karlsruhe - provavelmente a primeira conferência internacional realizada. Ao final do século dezenove, a descoberta do elétron (1897) e a possibilidade de "partir" um átomo, ambas decorrência dos trabalhos de Thomson (1856 - 1940), bem como os fenômenos radioativos - observados inicialmente em 1896 - possibilitaram a consolidação dos conceitos de átomo e de molécula.

Ainda que não percebido inicialmente, os estudos sobre a Radioatividade em muito contribuíram para a consolidação 
da Teoria Atômica. Em 8 de novembro de 1895 Röntgen (1845 - 1923) descobriu os raios-X. Num espaço de tempo de uma década é possível relacionar uma série de resultados estreitamente ligados à moderna Teoria Atômica: em 1896 Becquerel (1852 - 1908) observa a radioatividade, denominada por ele de "raios urânicos"; no mesmo ano Zeeman (1865 - 1934) analisa a influência dos campos magnéticos sobre as linhas espectrais; a relação entre a carga e a massa dos raios catódicos é determinada pelo já citado Thomson em 1897; no ano seguinte Rutherford (1871 - 1937) registra a existência de dois tipos de radioatividade (raios alfa e beta); neste mesmo ano M. Curie (1867 - 1934) refere-se à radioatividade como uma propriedade atômica; em 1899 Thomson, ao medir a carga dos elétrons emitidos, relaciona este fato à possibilidade do átomo ser quebrado; em 1900 Villard (1860 - 1934) descobriu os raios gama e em 1905 Einstein postula sobre o quantum de luz.

No que se refere à avaliação sobre o tamanho dos átomos o percurso é também longo. Em 1816 Young (1773 1829) estimou a dimensão da molécula da água como entre dois mil e dez mil milionésimos de polegada. Em 1866 Loschmidt (1821 - 1895) calculou o diâmetro da "molécula do ar" como da ordem de milionésimo de milímetro, enquanto Kelvin (1824 - 1907), em 1870, avaliou a molécula do hidrogênio como medindo cerca de $6 \times 10^{-8} \mathrm{~cm}$, um resultado similar encontrado no mesmo ano por van der Waals (1837 - 1923). Por volta de 1880 o tamanho da molécula do Hidrogênio e das demais componentes do ar situava-se na faixa de 1 a $2 \times 10^{-8} \mathrm{~cm}$, um valor bastante razoável se consideramos os valores atualmente aceitos $\left(2,0 \times 10^{-8} \mathrm{~cm}\right.$ para o diâmetro efetivo do átomo de Hidrogênio, $0,7 \times 10^{-8}$ cm para a distância entre os núcleos numa molécula de Hidrogênio). As primeiras imagens capazes de mostrar átomos individuais surgem na década de 50 (século XX), com o Microscópio Iônico de Campo (Field Ion Microscope - FIM).

A possibilidade primeira do homem "ver" os átomos está indelevelmente ligada a Erwin W. Müller. Para uma melhor compreensão de como funciona o FIM talvez seja útil comentar sobre o seu predecessor, o Microscópio de Emissão por Campo (Field Emission Microscope - FEM), bem como discorrer um pouco sobre como se distribuem os elétrons em um metal. Entre os elétrons que constituem um átomo, aqueles responsáveis pelas ligações químicas nas quais um átomo pode participar, são denominados de elétrons de valência, e são os elétrons mais externos do átomo. Os átomos de um metal podem, de um modo simplificado, ser representados conforme mostrado na Figura 1. Assim, num metal, os elétrons de valência "se separam" do respectivo átomo original formando quase que um "gás de elétrons" que permeia todo o metal, possuindo, portanto, grande liberdade de movimento - e isto está diretamente relacionado com a possibilidade de condução elétrica por parte dos metais. Os elétrons, a despeito desta grande mobilidade interna, não são capazes de deixar o metal. Estes elétrons não podem, portanto, sair do metal, a menos que recebam uma quantidade mínima de energia. Isto ocorre, por exemplo, quando se incide luz ultravioleta sobre um metal. Os elétrons que absorvem a energia cedida pela luz podem então escapar do metal que, portanto, se torna eletrizado positivamente. Isto é o denominado efeito foto-elétrico. Representando esquematicamente a energia dos elétrons de um metal (ver Figura
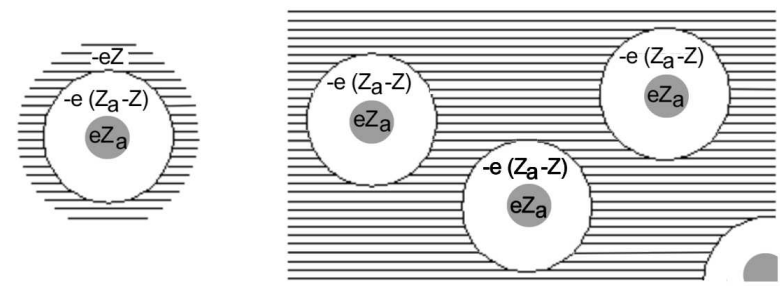

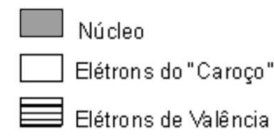

A)

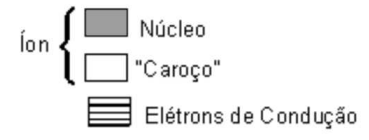

B)
Figura 1. a) Representação esquemática de um átomo isolado, com o núcleo, os elétrons mais profundos (elétrons do "caroço") e os elétrons que participam das ligações químicas (elétrons de valência). A figura não apresenta correspondência no que se refere aos tamanhos relativos, não estando portanto em escala. b) Em um metal o núcleo e os elétrons mais profundos essencialmente preservam a sua distribuição espacial, comparativamente com o á tomo isolado. Os elétrons de valência, no entanto, "deixam" os seus átomos originais, constituindo quase que um "gás de elétrons" com grande liberdade de movimento no interior do metal. (Adaptado do Livro Solid State Physics, de Ashcroft e Mermin).

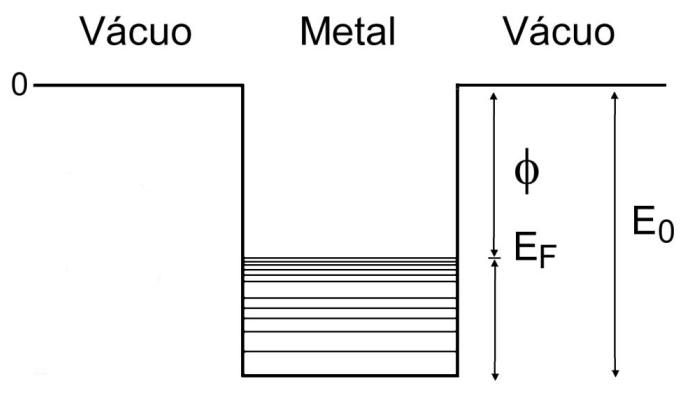

Figura 2. O "poço de potencial" e os níveis de energia dos elétrons "livres" de um metal. Os níveis de energia estão ocupados para uma energia $\mathrm{E} \leq E_{F}$ e vazios para $\mathrm{E}>E_{F}$, onde a energia do último nível ocupado é denominada de Energia de Fermi. A função trabalho, F, é a energia necessária para trazer um elétron da Energia de Fermi até o topo do poço de potencial, situação que corresponde a um elétron livre do metal e com energia cinética zero (repouso).

2), temos que, para que um elétron "escape" do metal, há necessidade que o mesmo absorva uma quantidade mínima de energia $\Phi$, e a esta energia mínima denominamos de função trabalho. Uma analogia para a situação dos elétrons, livres para se moverem no interior do metal, mas incapazes de escaparem dele, poderia ser feita imaginando uma bola solta numa superfície lisa, a partir do ponto A, como mostrado na Figura 3. Se a bola é solta (em repouso) a partir de A e se a superfície é lisa, a mesma pode se mover livremente entre os pontos A e B, não possuindo portanto energia suficiente para atingir o ponto $C$, não sendo também capaz 
de, ultrapassando $\mathrm{C}$, atingir a plataforma horizontal da direita. Para que a bola se "libertasse" do poço e atingisse C, podendo assim escapar para a plataforma horizontal, seria necessário que lhe fornecêssemos um adicional de energia.

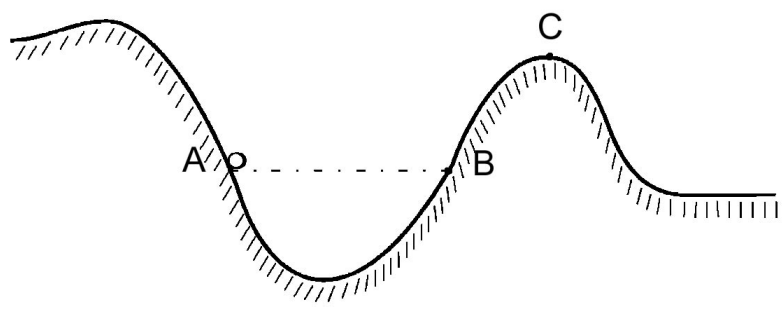

Figura 3. Uma bolinha solta em repouso a partir do ponto A, numa rampa lisa, no máximo alcança o ponto B. Para escapar para a plataforma da direita seria necessário fornecer-lhe uma energia adicional.

a)

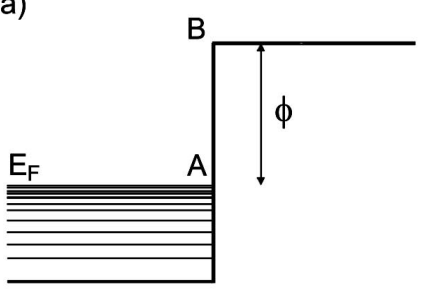

b)

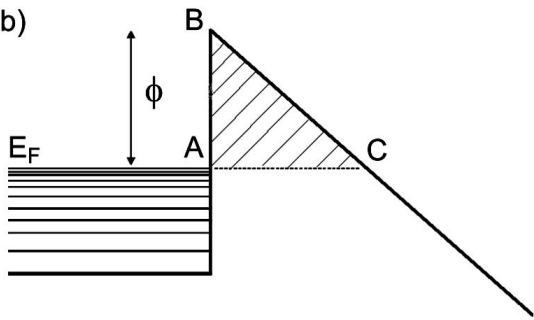

c)

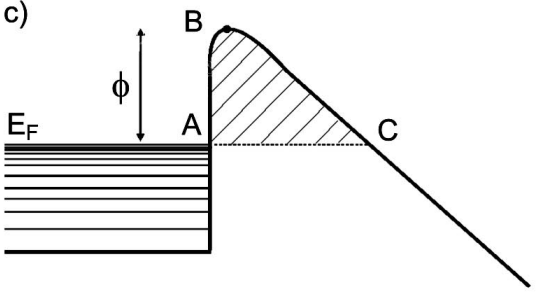

Figura 4. a) Energia potencial de um elétron de valência de um metal sem a aplicação de um campo elétrico externo. (b e c) - Energia potencial de um elétron com aplicação de campo externo. b) Forma aproximada (triangular) e c) Forma mais precisa (rombuda).

Os elétrons são partículas carregadas de eletricidade e, portanto, sofrem forças se sobre eles é aplicado um campo elétrico. Assim, o diagrama representativo da energia potencial de um elétron em um metal, que no caso sem aplicação de um campo elétrico é representado na Figura 4.a, resulta modificado pela aplicação do campo, tendo então o aspecto representado nas Figuras 4.b e 4.c. A figura 4.b representa uma aproximação mais grosseira, enquanto 4.c corresponde a uma situação mais realista. É possível então comparar o caso da bolinha solta na rampa com o do elétron de valência em um metal. Para que a bolinha atinja o ponto $\mathrm{C}$, ou para que ela o ultrapasse, chegando à plataforma horizontal, é necessário que, ao longo do percurso entre A e B, um mínimo de energia lhe seja concedida (desde que ela tenha sido abandonada, em repouso, no ponto A). Uma situação que é análoga à do elétron do metal com maior energia (nível de Fermi), que assim precisaria receber pelo menos uma quantidade $\Phi$ de energia para que possa sair do metal. O campo elétrico externo aplicado não modifica essencialmente a energia dos elétrons no interior do metal, uma vez que o campo elétrico "não penetra" no metal. Como mostrado na figura 4, a energia potencial do elétron, no interior do metal, com ou sem campo externo aplicado, é essencialmente a mesma.

Em escala atômica, as Leis da Física que são capazes de explicar os fenômenos em escala macroscópica - aquelas correspondentes às dimensões com as quais os nossos sentidos podem lidar - nem sempre são adequadas. Uma situação que constitui um bom exemplo disto é a do chamado efeito túnel. Se a bolinha do nosso exemplo for de fato abandonada no ponto $\mathrm{A}$, e desde que ela não receba energia no percurso de $\mathrm{A}$ até $\mathrm{B}$, não há hipótese dela ultrapassar $\mathrm{C}$ ou atingir a plataforma horizontal. Não é, no entanto, o que ocorre com o elétron do nosso exemplo. A Mecânica Quântica área da Física adequada ao trato de fenômenos em escala atômica e sub-atômica - estabelece como possível que um elétron de valência do metal, com energia igual ou mesmo inferior à energia de Fermi, consiga fazer o percurso entre $\mathrm{A}$ e $\mathrm{C}$, mesmo sem receber alguma energia adicional, como seria necessário no caso da bolinha. Este fenômeno é probabilístico, i. e., a Mecânica Quântica estabelece a chance disto ocorrer, não sendo, por conseguinte, um fato determinístico, como no caso previsto pelas Leis da Física adequadas à escala macroscópica - as Leis de Newton. Esta probabilidade de transição entre $\mathrm{A}$ e $\mathrm{C}$ depende fortemente do que se chama de barreira de potencial - a região hachurada das Figuras 4, b e c. Assim, quanto maior a intensidade do campo elétrico externo - o que corresponde a uma região hachurada menor, o que faz com que a reta da direita seja mais inclinada - maior a probabilidade que o elétron tem de sofrer a transição entre A e C. Num processo probabilístico, se o fenômeno se repete para muitos corpos (no caso elétrons), uma fração de sucesso (ou de insucesso) ocorre em proporção correspondente à probabilidade de ocorrência (ou de não ocorrência).

Consideremos um metal, com a superfície separatriz entre o mesmo e o ar (ou vácuo por simplicidade), essencialmente plana, e bem grande nas dimensões da superfície. A aplicação de um campo elétrico externo, perpendicular à superfície (apontando para ela), resulta em uma densidade superficial de carga elétrica que, esquematicamente representada, é mostrada na Figura 5. Para uma superfície metálica plana, a densidade superficial de carga $\sigma$ (carga elétrica por unidade de área) é constante, bem como a intensidade do campo elétrico na vizinhança da superfície, desde que esta possua dimensões bem maiores que a distância do ponto considerado à superfície. A intensidade do campo 
elétrico - neste caso constante - pode ser "visualizada" pela concentração das linhas de força, conforme mostrado na Figura 5. A presença de irregularidades na superfície do metal acarreta uma variação local da densidade de carga e do

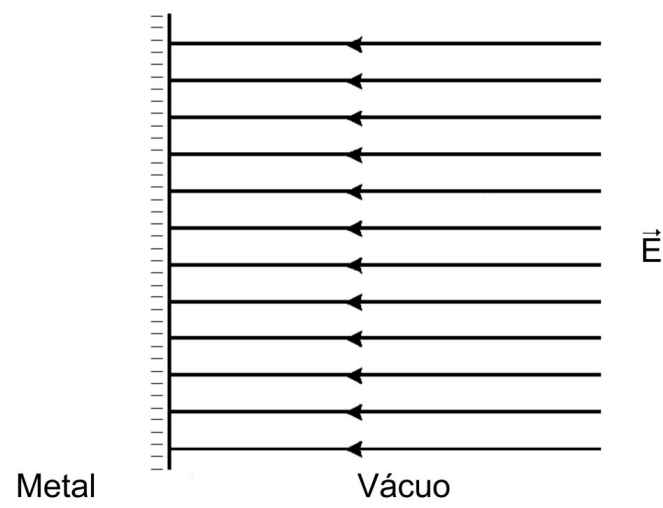

Figura 5. Superfície de separação entre um metal e o vá cuo. Há, na região exterior ao metal, um campo elétrico uniforme, de sorte que uma densidade superficial de carga constante se faz presente na interface. A figura também mostra as linhas de força do campo elétrico aplicado.

campo elétrico, ambos apresentando um incremento - comparado com porções planas do condutor - na vizinhança destas irregularidades. A Figura 6 representa esquematicamente a situação de uma protuberância de forma hemisférica superimposta a uma superfície plana. A intensidade do campo elétrico no ponto A (topo da meia esfera) é, para esta geometria, três vezes maior que no ponto B (ponto da superfície bem afastado da meia esfera). Em virtude do aumento local da densidade de carga e do campo elétrico na vizinhança de uma protuberância, o fenômeno de tunelamento (emissão) de elétrons a partir de uma região como esta (ponto A) fica significativamente aumentada, se comparamos com a situação próxima de uma região plana (ponto B). Este é o fenômeno físico em que se baseia o funcionamento do Microscópio de Emissão por Campo - FEM.

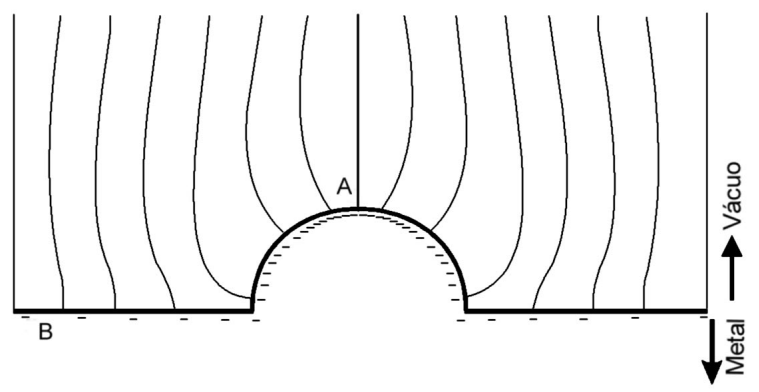

Figura 6. Região da superfície separatriz entre um metal e o vácuo. A superfície em grande parte é plana, apresentando uma protuberância na forma de uma meia esfera. No ponto A (topo da meia esfera) a intensidade do campo elétrico é três vezes maior que em B (ponto da superfície plana - bem afastado da protuberância mas ainda distante do bordo da superfície).

O FEM, idealizado por E. W. Muller, foi o primeiro instrumento concebido com a expressa intenção de ten- tar visualizar uma superfície numa escala correspondente ao domínio das dimensões atômicas, além de, simultaneamente, ser possível acompanhar a ocorrência de mudanças que se desenvolvem na superfície. Müller, na concepção do FEM, explorou o já então conhecido fato de que a densidade super-

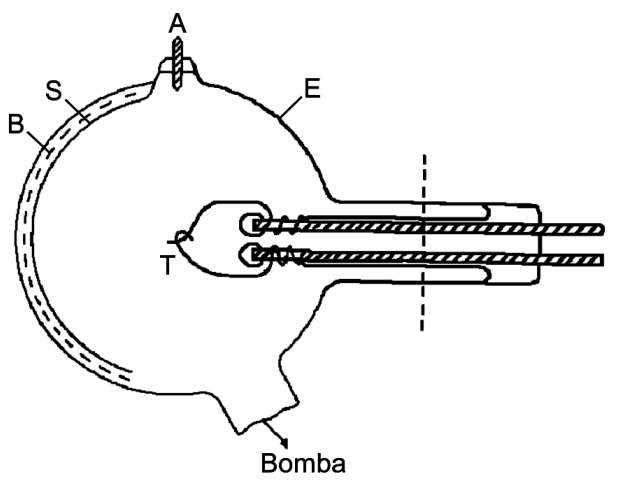

Figura 7. Esquema simplificado do FEM. E corresponde à parede da câmara - originalmente de vidro, nas versões atuais de aço. $S$ é a tela fosforecente, $B$ representa uma camada de óxido de Estanho, $A$ o ânodo e $T$ a ponta emissora (amostra).

ficial de carga e a intensidade do campo elétrico ficam sensivelmente aumentadas na vizinhança das pontas de um condutor; diferentemente do potencial elétrico que é o mesmo. Constituem aplicações comuns deste fato, as antenas e os pára-raios. Na sua concepção mais simples, o FEM consiste de um bulbo com geometria esférica, coberto internamente com uma tela fosforescente e condutora. No centro do bulbo é colocada uma ponta metálica, bastante afiada e condutora, que constitui a amostra a ser observada. A pressão interna do bulbo é mantida na faixa de $10^{-7}$ a $10^{-11}$ torr (1.0 torr corresponde a $1 \mathrm{~mm}$ de $\mathrm{Hg}$, enquanto a pressão atmosférica padrão é de $760 \mathrm{~mm}$ de $\mathrm{Hg}$, portanto 760 Torr). A unidade padrão de pressão é, na verdade, o Pascal (Pa), que corresponde à força de 1,0 Newton distribuída em $1,0 \mathrm{~m}^{2}$. A correspondência entre estas unidades é de 1,0 torr $=1,333 \times$ $10^{2} \mathrm{~Pa}$. O torr, no entanto, é a unidade comumente empregada na tecnologia de vácuo. Um esquema simplificado do FEM é mostrado na Figura 7. A ponta (amostra) metálica possui, na sua extremidade máxima, um raio da ordem de $10^{-7}$ a $10^{-6} \mathrm{~m}$ e uma diferença de potencial da ordem de $10^{4}$ Volts é aplicada entre a ponta e a tela fosforescente. A intensidade do campo elétrico (da ordem de $1 \mathrm{~V} / \mathrm{nm}$ ou um pouco mais) é assim suficiente para promover o tunelamento de elétrons a partir da amostra. Os elétrons deixam o metal com pequena energia cinética (baixa velocidade) e, a partir daí, são acelerados em direção à tela. Esta emissão, denominada de emissão fria ("cold emission"), decorre da ação do campo elétrico externo mediante o tunelamento dos elétrons, não devendo ser confundida com a emissão estimulada - seja pela ação de radiação eletromagnética (efeito fotoelétrico) ou de aquecimento (emissão termoiônica). Como a velocidade com que os elétrons deixam o metal é baixa e como o campo elétrico aplicado, é, na superfície da amostra, perpendicular à mesma, os elétrons seguem, da amostra para a tela, uma trajetória muito aproximadamente equivalente 
à das linhas de força do campo externo, como é esquematicamente representado na Figura 8. O aumento então, mostrado na tela, é aproximadamente dado por $\mathrm{D} / \delta=\mathrm{x} / \mathrm{r}$, sendo possível obter aumentos da ordem de $10^{5}-10^{6}$ vezes. A resolução é, no entanto, limitada a cerca de 20 angstroms $\left(1,0\right.$ Angstrom $\left.=10^{-10} \mathrm{~m}\right)$. Isto leva a que o equipamento é

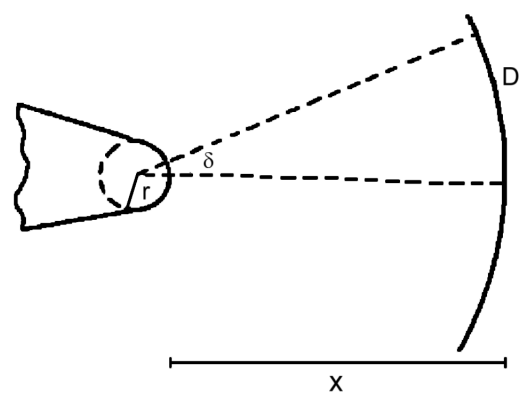

Figura 8. Diagrama representando o esquema ótico em que se baseia o FEM, com $r$ sendo o raio de curvatura da extremidade da amostra e $x$ a distância entre amostra e tela. Uma porção da amostra, de dimensão linear $d$, será aumentada, correspondendo na tela a uma distância D. O fator de aumento linear é pois, aproximadamente, $D / d$.

incapaz de fornecer uma resolução em escala atômica (poucos angstroms). Fica por este meio impossibilitada a visualização de átomos individuais, mas apenas de agregados de átomos, capazes, no entanto, de identificar planos atômicos com a sua respectiva orientação. A incapacidade do FEM em fornecer imagens com resolução atômica levou Müller a buscar uma outra alternativa. Em 1928 Oppenheimer (o mesmo que mais tarde dirigiu o Projeto Manhattan, que resultou na primeira bomba atômica) havia previsto que um átomo isolado poderia ser ionizado (pela perda de um dos seus elétrons) como resultado da aplicação de um campo elétrico externo. Esta previsão permaneceu, por vários anos, como apenas um exercício teórico, de comprovação experimental dificultada em razão da magnitude necessária para o campo elétrico (da ordem de 10 $\mathrm{V} / \mathrm{nm}=10^{10} \mathrm{~V} / \mathrm{m}$ ), ser àquela época inacessível do ponto de vista prático. Os experimentos com o FEM vieram a sugerir procedimentos que tornava possível obter intensidades maiores de campo elétrico. Em 1941 Müller observou que, invertendo a polaridade de operação do FEM, e aumentando substancialmente a tensão, era possível observar a dessorção (ou evaporação) de átomos da amostra, tendo então tentado obter uma imagem da amostra como resultado da emissão dos átomos dessorvidos/evaporados, que radialmente se deslocavam em direção à tela em trajetórias aproximadamente radiais. A imagem obtida na tela, resultado do processo de dessorção/evaporação, era por demais tênue, dado ao reduzido número de átomos emitidos. No intuito de promover o suprimento dos átomos dessorvidos, e assim manter o processo de emissão, foi introduzido na câmara um gás - Hidrogênio. Isto levou a que, em 1951, fossem obtidas as primeiras imagens com o então denominado Field Ion Microscope. A Figura 9 reproduz a capa de folheto de um evento comemorativo dos 50 anos do FIM, mostrando a página inicial do primeiro artigo sobre o equipamento. Há razão para se acreditar não haver, àquela época, clareza da parte de Müller, sobre se as imagens formadas resultavam de átomos da amostra que eram dessorvidos/evaporados ou de átomos do gás, estes ionizados pela ação do campo elétrico. A segunda possibilidade veio, mais tarde, a se mostrar como a correta.

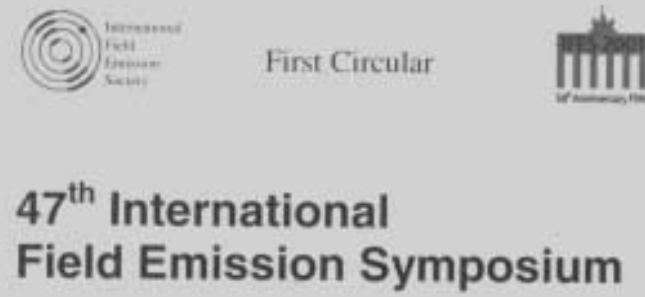

July 29 - August 3, 2001

Berlin, Germany

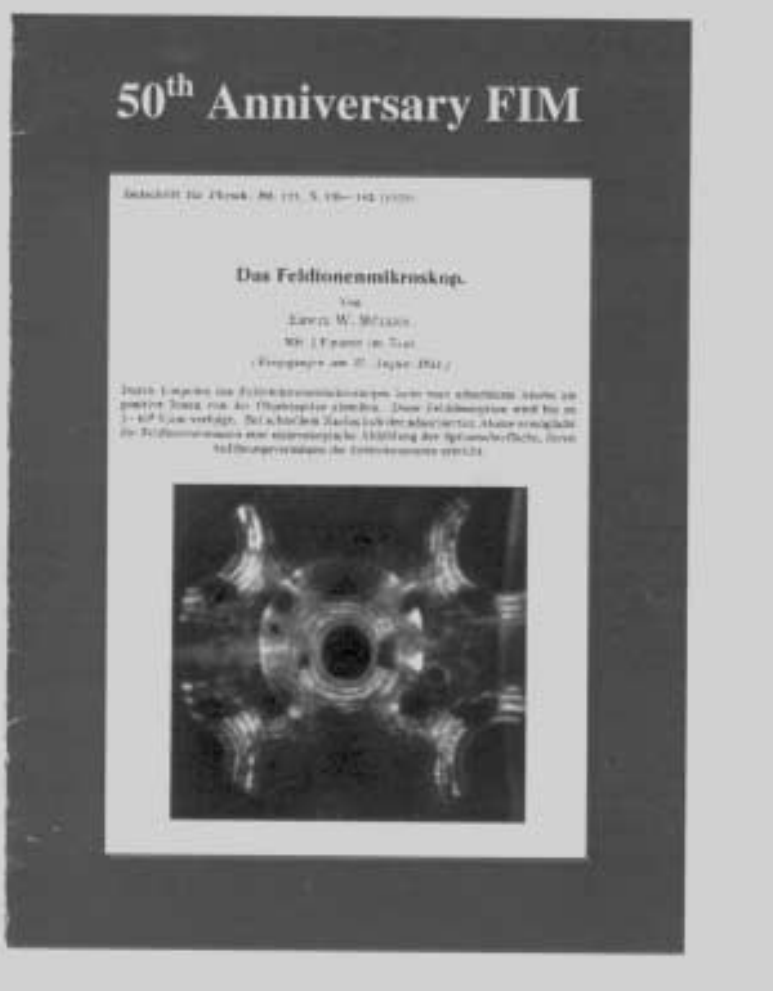

Figura 9. "Fac-símile" de "folder" do International Field Emission Symposium, realizado em julho de $2001 \mathrm{em}$ Berlim, quando sessão comemorativa aos 50 anos do FIM foi realizada. A foto foi retirada da publicação: E. W. Müller, Z. Phys. 131 (1951) 136. Tradução do texto em alemão: Através da troca de polaridade do microscópio de emissão de campo, é possível remover átomos adsorvidos na forma de íons positivos da ponta do objeto. Essa dessorção é realizada por campos de até $3 \times 10^{-8} \mathrm{~V} / \mathrm{cm}$. Com reposição rápida dos átomos adsorvidos a emissão de íons de campo possibilita uma imagem microscópica da superfície da ponta, cuja capacidade de resolução alcança a constante de rede.

Uma situação que se presta, como exemplo simples, para a explicação do fenômeno de ionização por campo é a do átomo de Hidrogênio. Um elétron, com energia $E_{i}$ em 
um átomo de Hidrogênio, apresenta uma energia potencial como a representada na Figura 10. Uma possibilidade para que o elétron deixe o átomo, que assim se tornaria ionizado, seria a de que a ele fosse fornecida uma energia, no mínimo,

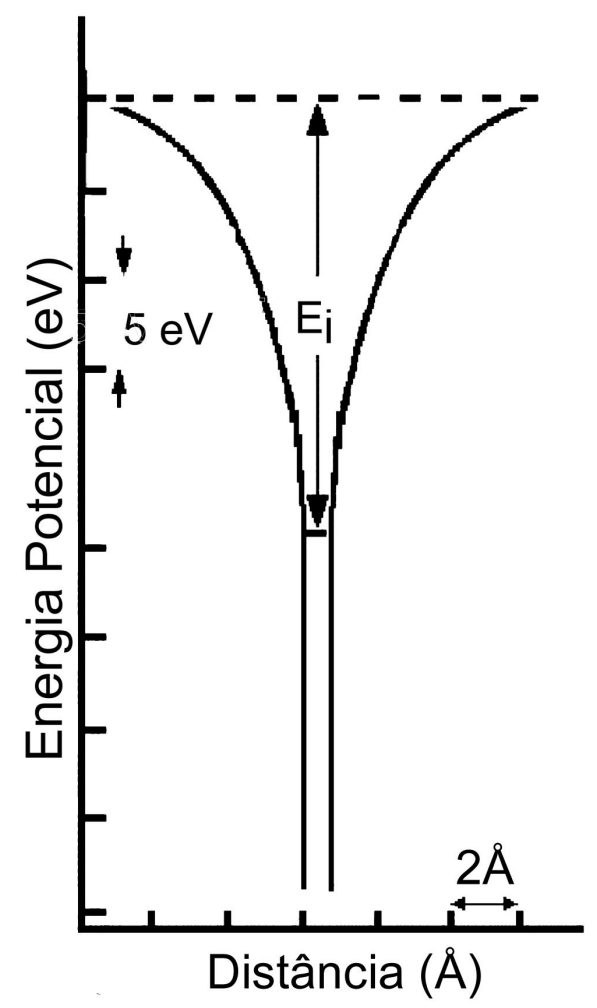

Figura 10. Esquema aproximado representativo da energia potencial de um elétron de um átomo de Hidrogênio no espaço livre.

igual a $E_{i}$. Com o átomo de Hidrogênio (no espaço livre, distante, portanto, de outras influências) submetido apenas à ação de um campo elétrico externo, o diagrama da energia potencial fica modificado, como mostra a Figura 11. Vemos assim que, numa direção, a barreira de potencial é reduzida e o elétron passa a ter uma probabilidade não nula de escapar do átomo, que assim seria ionizado pela ação do campo elétrico, prescindindo desta maneira do fornecimento de uma energia $E_{i}$. A transição eletrônica (tunelamento) só é significativa quando o campo elétrico for elevado o suficiente para que a barreira de potencial seja reduzida, de tal forma, que a mesma tenha uma largura que possibilite uma probabilidade de transição não muito pequena. Campos elétricos de alguns volts/angstroms (algumas dezenas de volts/nm) são necessários e as dificuldades tecnológicas em se produzir campos desta intensidade foram a causa para que cerca de uma década tenha decorrido entre a previsão teórica de Oppenheimer e os primeiros trabalhos experimentais de Müller. Se o átomo de Hidrogênio, em lugar de isolado, sofrendo apenas a ação do campo elétrico externo, estiver próximo a uma superfície condutora (um metal, por exemplo), o diagrama correspondente à energia potencial do elétron é aproximadamente como representado na Figura 12. A curva representativa da energia potencial apresenta, assim, continuidade entre a posição fora do metal e no interior deste (comparar com a Figura 2 que mostra a energia de Fermi num metal). A barreira de potencial se estreita à me- dida que o átomo está mais próximo da superfície, aumentando assim a probabilidade de um elétron "saltar" do átomo para a superfície metálica, com subseqüente produção de um íon. O Microscópio Iônico de Campo (Field Ion Microscope - FIM) utiliza então do fenômeno da ionização por campo para a produção de imagens de superfícies. Um esquema

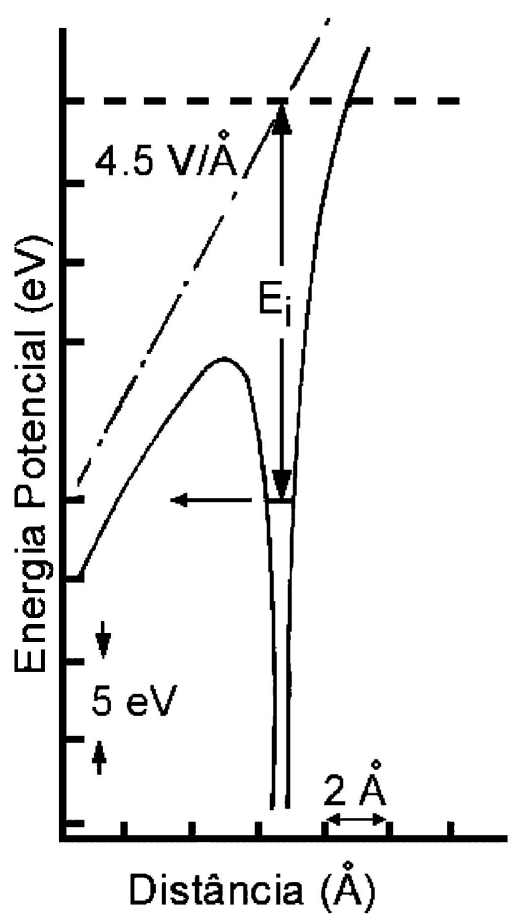

Figura 11. Aproximação para a energia potencial de um elétron em um átomo de Hidrogênio no espaço livre, sujeito à ação de um campo elétrico externo.

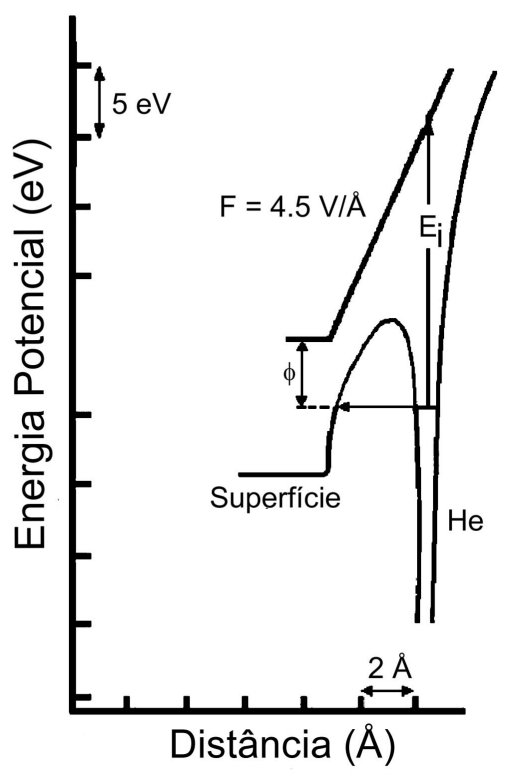

Figura 12. Energia potencial para o mesmo átomo da figura anterior, sujeito à ação do campo elétrico externo, mas na vizinhança de um metal cuja função trabalho é F. A situação mostrada corresponde ao caso onde o nível de energia do elétron do átomo encontra-se alinhado com o nível de Fermi do metal. 
simplificado do FIM é mostrado na Figura 13. Entre a ponta, que constitui a amostra a ser observada, e a tela (cerca de 10 $\mathrm{cm}$ distante da amostra) é aplicada uma tensão (diferença de potencial) entre 3,0 e 30 kilovolts, o que faz com que próximo à amostra ocorram campos da ordem de algumas poucas unidades de volt/angstrom (algumas dezenas de volt $/ \mathrm{nm}$ ). A polaridade neste caso é inversa, comparada com o FEM. Um gás é inserido na câmara (pressão da ordem de $2 \times 10^{-3} \mathrm{~Pa}$ ) e seus átomos restam fortemente polarizados, sendo assim atraídos em direção à amostra. Após um processo de acomodação, com conseqüente redução da sua velocidade, os átomos fortemente polarizados apresentam maior probabilidade de serem ionizados pela ação do campo. Isto majoritariamente ocorre nos locais onde a intensidade do campo elétrico é maior, isto é, logo acima dos átomos mais protuberantes da amostra. Os íons produzidos são acelerados em direção à tela, onde se forma uma imagem que revela o contraste resultante dos locais onde há maior ou menor produção de íons, refletindo assim as posições dos átomos mais protuberantes. A montagem do equipamento é mostrada na Figura 13, enquanto o que ocorre na vizinhança da superfície é esquematicamente representado na Figura 14. A elevada curvatura da amostra, relativamente à curvatura da tela, faz com que as linhas de força do campo elétrico sejam altamente divergentes. A Figura 15 mostra uma imagem típica obtida com o FIM. A obtenção de imagens, com resolução capaz de se poder identificar átomos individuais, não foi um processo simples, como a explanação até agora dada poderia sugerir. Em 1951 Müller publicou seu primeiro artigo a respeito do FIM (ver Figura 9), descrevendo a sua estrutura básica, bastante semelhante à do seu predecessor, o FEM, com a adição de Hidrogênio como gás formador da imagem. Já aí ele enfatizava a necessidade de resfriar o equipamento como forma de melhorar a resolução espacial, fazendo também referência a que experimentos onde o Hidrogênio era substituído pelo Hélio estariam sendo realizados. Estas providências buscavam, pelo emprego de um átomo mais pesado $(\mathrm{He})$ que o Hidrogênio, melhorar a resolução do equipamento. Assim, aparentemente, quase todos os ingredientes para a obtenção de resolução em escala atômica estavam já presentes. Neste mesmo ano Müller transferiu-se de Berlim para o Pennsylvania State College, o que atualmente corresponde à Pennsylvania State University. Por esta época os equipamentos eram essencialmente constituídos de câmaras de vidro, em lugar das atuais, construídas com aço e dispondo de janelas de quartzo. Por volta de 1954 quase todos os membros do grupo de Müller estavam ainda envolvidos com FEMs, enquanto apenas Müller e um dos seus estudantes, Kanwar Bahadur, estavam diretamente envolvidos com o FIM. Um dos demais estudantes de então, Allan Melmed, relembra em um vívido e interessante testemunho [1], a atmosfera prevalecente àquela época no laboratório de Müller. Registra por exemplo que, ao longo de mais ou menos um ano, vários estudantes teriam sugerido a Müller um expressivo resfriamento de todo o sistema, com o objetivo de melhorar a resolução. A idéia deles, e de Bahadur em particular, resultava de uma observação experimental segundo a qual, mesmo um pequeno acréscimo na temperatura, era ca- paz de degradar significativamente a qualidade da imagem. Raciocinando portanto em sentido contrário, poder-se-ia esperar que a redução da temperatura possibilitaria melhorar a resolução. Invariavelmente, segundo relata Melmed, Müller retrucava alegando que as idéias apresentadas pelos estudantes estavam, por uma ou por outra razão, erradas, o que freqüentemente deixava os estudantes "de cabeça baixa". A julgar por tal testemunho, é possível inferir que o chefe do laboratório desejava, sistematicamente, impregnar a todos com a idéia de que todas as boas idéias a respeito do FEM e do FIM eram, invariavelmente, suas. Era como se "ele já tivesse feito tudo, antes".

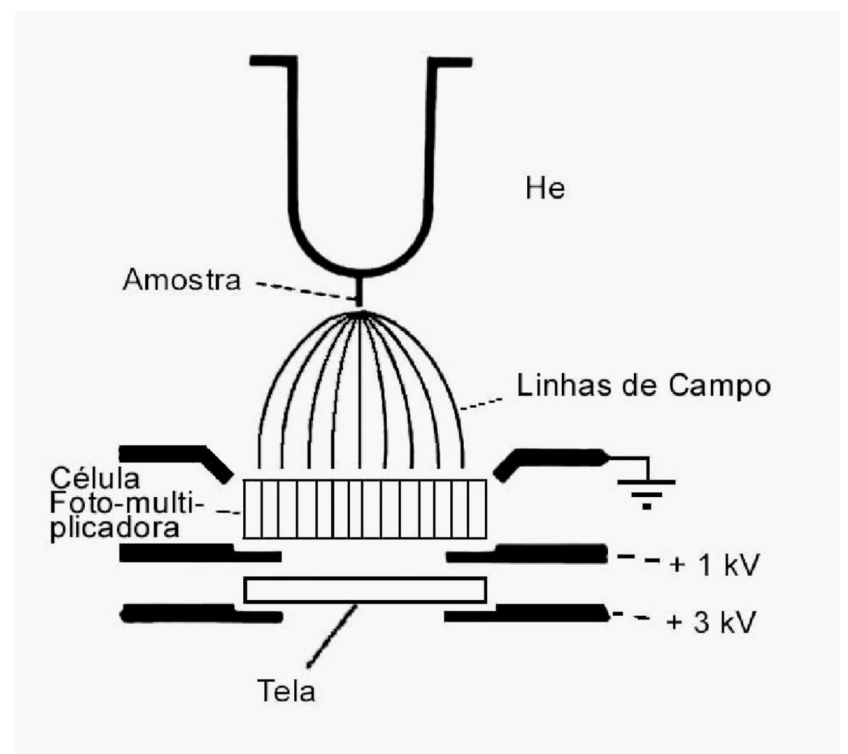

Figura 13. Diagrama simplificado do FIM. Este esquema contém um aperfeiçoamento, incluído bem depois das primeiras imagens com resolução atômica, destinado à intensificação das imagens formadas.

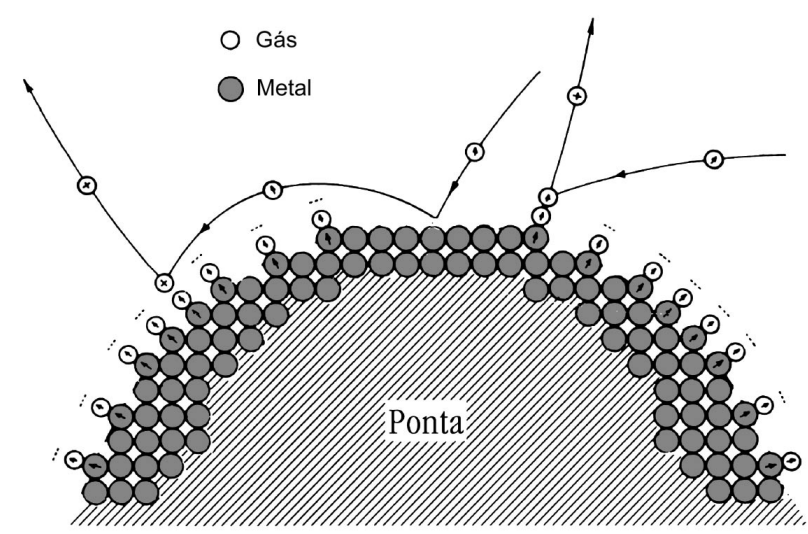

Figura 14. Átomos do gás formador da imagem são polarizados pela ação do campo elétrico e atraídos para a vizinhança da amostra. Na região imediatamente acima dos átomos mais protuberantes a intensidade local do campo elétrico é maior e portanto aí há maior probabilidade de ionização dos átomos do gás. Estes, após ionizados, são acelerados em direção à tela onde o contraste entre regiões com maior e menor intensidade do campo aparece. 


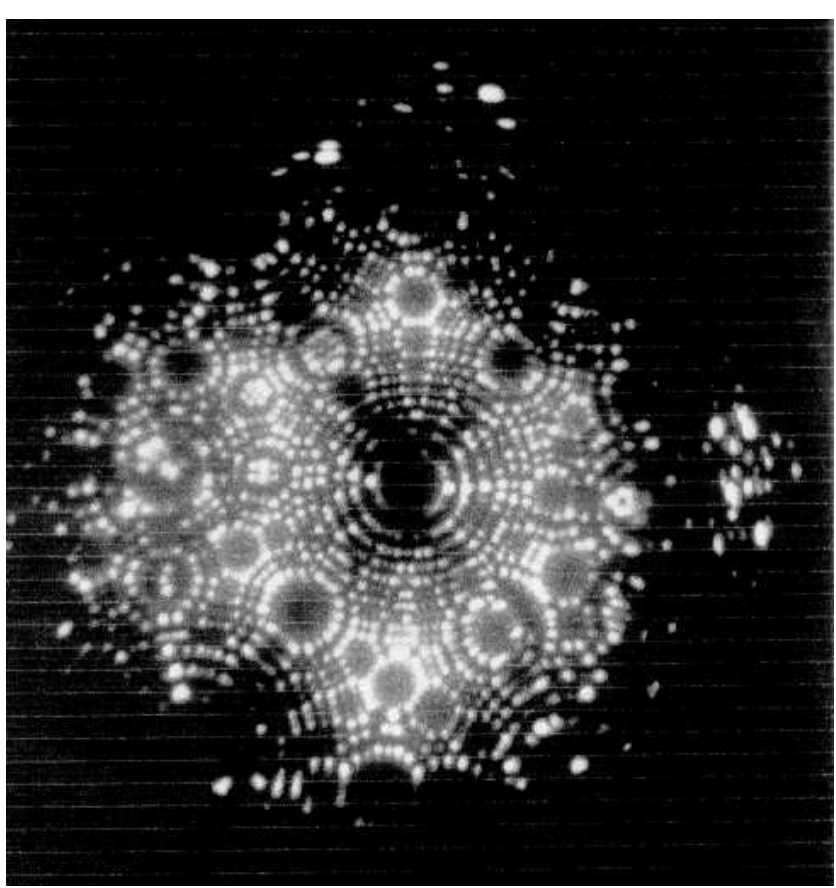

Figura 15. Imagem típica obtida com o FIM. No caso trata-se de uma amostra de Tungstênio, tendo sido utilizado o He como o gás formador da imagem e a temperatura da amostra é de $40 \mathrm{~K}$, sendo a tensão aplicada de $4,5 \mathrm{kV}$. (Foto gentilmente cedida por G. W. Smith e colaboradores, Department of Materials, University of Oxford, U. K.).

Duas principais concepções dominavam os primeiros anos do FIM, na busca de uma verdadeira resolução atômica:

i) o mecanismo de formação da imagem resultava da dessorção/evaporação de átomos que, depois de adsorvidos na superfície, eram emitidos na forma de íons positivos, com o gás formador da imagem funcionando apenas como fonte de reabastecimento para os sítios liberados com a dessorção/evaporação;

ii) para a formação da imagem da superfície era necessário remover primeiro qualquer contaminação superficial bem como toda rugosidade eventualmente presente, sendo isto feito mediante o aquecimento da amostra (tratamento térmico - "annealing").

Não obstante, tudo leva a crer que, de fato, Müller concebia, pelo menos até 1954, o FIM como sendo um microscópio que tinha como princípio básico para o seu funcionamento a dessorção/evaporação de átomos - seria assim um "Field Desorption Microscope". Melmed [1], argüi como possível que isto explique a sua recusa inicial em reduzir a temperatura do equipamento com o intuito de buscar uma melhor imagem, como sugerido por alguns dos seus estudantes. Em 1953 Müller relata que Dreschler e Pankow teriam mergulhado um FIM em Nitrogênio líquido, sem que nenhuma melhora na imagem fosse observada, decorrente do resfriamento, comparando com o caso em que o equipamento operava à temperatura ambiente. Melmed qualifica como "curioso" o fato de que, a despeito da publicação de 1951 mencionar experimentos com He como em realização, isto na verdade só mais tarde foi feito, mas desta feita por Dreschler e Pankow em Berlim e publicado em 1954. A utilização de He como gás formador da imagem representou um passo importante no que viria a ser mais tarde a obtenção de imagens com resolução atômica. Até então, no entanto, a idéia de que o mecanismo básico para a formação da imagem resultava de um processo de dessorção prevalecia. Em 1954, um trabalho fundamental por parte de Ingrahm e Gomer mostrou que, na verdade, os íons formadores da imagem tinham origem numa estreita região poucos angstroms acima da amostra, conforme mostrado na Figura 14. Um golpe que se mostrou definitivo na interpretação de que o FIM funcionava a partir de um processo de dessorção.

Pouco tempo depois, em junho de 1954, Müller e Bahadur tentaram obter imagens com o FIM essencialmente imerso em nitrogênio líquido, sem no entanto obterem uma melhor resolução, apesar da imagem aparecer mais brilhante. Melmed relata [1] que, pouco depois e a despeito deste insucesso, Bahadur começou a, de alguma maneira, ter a expectativa de que o resfriamento da ponta (amostra) poderia representar alguma diferença. Müller, ainda segundo Melmed, não se mostrou convencido desta possibilidade, mas aquiesceu, permitindo que um novo experimento fosse realizado por Bahadur. Em um trabalho submetido a publicação no início de setembro de 1955, mas efetivamente publicado em 1956, Müller e Bahadur apresentam resultados de uma amostra de Tungstênio com raio de curvatura da ordem de $20 \mathrm{~nm}$ que tinha sido aquecida e parcialmente submetida a evaporação por campo. Este resultado, como mais tarde se verificou, estava muito próximo da obtenção da resolução atômica, mas os próprios autores manifestavam dúvidas a este respeito. O continuado pessimismo de Müller sobre a utilidade de efetuar o resfriamento da amostra, procedimento que depois se mostrou essencial para se conseguir resolução atômica, pode ser compreendido em se considerando as duas tentativas anteriores que se mostraram infrutíferas e o fato de que considerações teóricas não indicavam tal melhoria como possível de se esperar a partir do processo de resfriamento. Em 11 de outubro de 1955, ainda segundo o relato de Melmed, a ansiedade era grande no laboratório. Bahadur convidou Müller à sala onde a sua mais recente montagem havia sido instalada. As condições de observação então existentes exigiam um período de acomodação à necessária escuridão do ambiente, posto que as imagens formadas eram por demais tênues só bem mais tarde um procedimento de intensificação da imagem foi acoplado ao equipamento. Alguns outros estudantes, que sabiam ou desconfiavam do que estava ocorrendo, nervosamente aguardavam do lado de fora. Ao ver as imagens formadas, de acordo com relato posterior de $\mathrm{Ba}-$ hadur, Müller pronuciou o que hoje pode ser traduzido como "é isto ấ" ("This is it", literalmente). Ao sair da sala Müller falava, como que para si mesmo: "Atoms, ja atoms". A atmosfera no laboratório era de completa e total excitação e alegria. A expectativa de um prêmio Nobel para Müller pairava na cabeça de muitos - o que acabou não se confirmando. Logo após houve a divulgação sobre o sucesso do FIM. Poucas semanas depois Müller fez um anúncio público do fato durante uma conferência (Ann. Meeting Electron 
Microscope Soc. Of America, Pennsylvania State University, 27 a 29 de Outubro de 1955), tendo a seguir submetido para publicação dois artigos [2, 3] onde ele aparece como único autor. No início de 1956 Kanwar Bahadur retornou ao seu país natal, a Índia, após defesa da sua tese de doutorado, intitulada Experimental Investigation of Field Ion Emission.

No já mencionado artigo de Melmed [1], ele chama a atenção para dois aspectos, de certa forma intrigantes, a respeito do desenvolvimento do FIM, desde o artigo original de 1951 até a obtenção de resolução atômica em outubro de 1955, quais sejam: i) Qual a razão para um período de 5 anos ter decorrido entre a invenção do FIM (1951) como um microscópio operante à temperatura ambiente e a obtenção de resolução atômica, operando a baixa temperatura, especialmente se é considerado o fato de que no artigo original é feita menção de que outros experimentos (especificamente mencionando o uso de $\mathrm{He}$ ) estavam em realização? ii) Qual a razão para que os dois primeiros experimentos com o FIM, operando a baixa temperatura, não tenham sido capazes de fornecer resolução atômica? Quanto à primeira questão restam apenas especulações. A resposta à segunda pergunta reside no fato de que o processo de evaporação por campo ("field evaporation"), à temperatura ambiente ou mais baixa, não tinha ainda estabelecida a sua utilidade. O processo de limpeza da amostra era anteriormente feito por aquecimento ("thermal annealing"). Em condições atuais de experimentação é possível mostrar imagens de uma mesma amostra, obtidas a baixa temperatura, com apenas o tratamento térmico ou com ele seguido de evaporação por campo, e que resultam em imagens bem distintas, sendo que o primeiro processo é incapaz de fornecer resolução atômica. Assim, a utilização da evaporação por campo a baixa temperatura, no processo de preparação da amostra para se obter resolução atômica, é absolutamente essencial. O que é estranho é que este fenômeno tenha demorado tanto tempo para ser observado, mesmo nas condições de então. As reduzidas dimensões da amostra, e a necessidade de que as mesmas tenham a forma de uma ponta extremamente fina, requerem cuidado e procedimentos muito específicos para a preparação da amostra a ser examinada. A Figura 16 mostra uma imagem obtida por microscopia eletrônica de uma amostra nas condições de uso para a obtenção de imagens com o FIM.

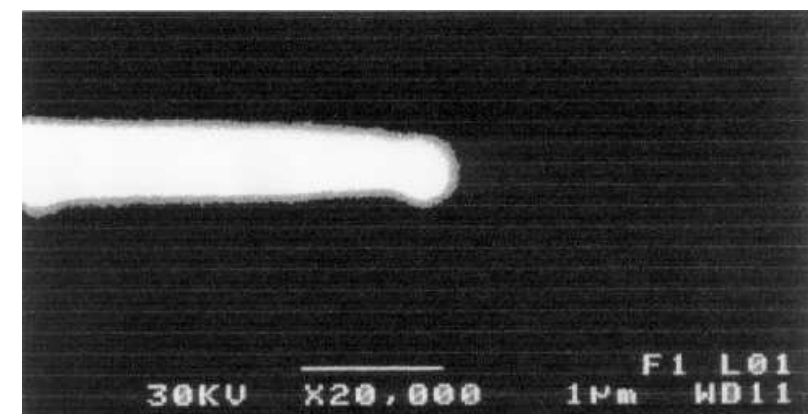

Figura 16. Imagem da extremidade de uma amostra de Ródio utilizada em FIM. A imagem foi obtida por microscopia eletrônica, com um aumento de 20000 vezes. (Foto gentilmente cedida por Dr. T. Visart - Université Livre de Bruxelles - Bélgica)

No processo de evaporação por campo (também denom- inado dessorção induzida - ver vocabulário), um pulso no sentido de fazer rapidamente crescer e decrescer a tensão aplicada à amostra é produzido. Fazendo isto corresponder a campos elétricos suficientemente elevados na superfície da amostra, átomos podem ser removidos do material. Os átomos mais proeminentes são ionizados e assim "arrancados" da amostra e acelerados em direção à tela (ou detector). Atualmente as taxas de evaporação induzidas pela aplicação de um campo elétrico podem ser cuidadosamente controladas, de tal forma que apenas poucos átomos podem ser removidos a cada pulso de tensão. Na seqüência mostrada na Figura 17, um único átomo é removido do plano atômico mais externo, entre as sucessivas tomadas. O processo pode também ser utilizado para limpeza controlada de contaminantes depositados sobre uma superfície.

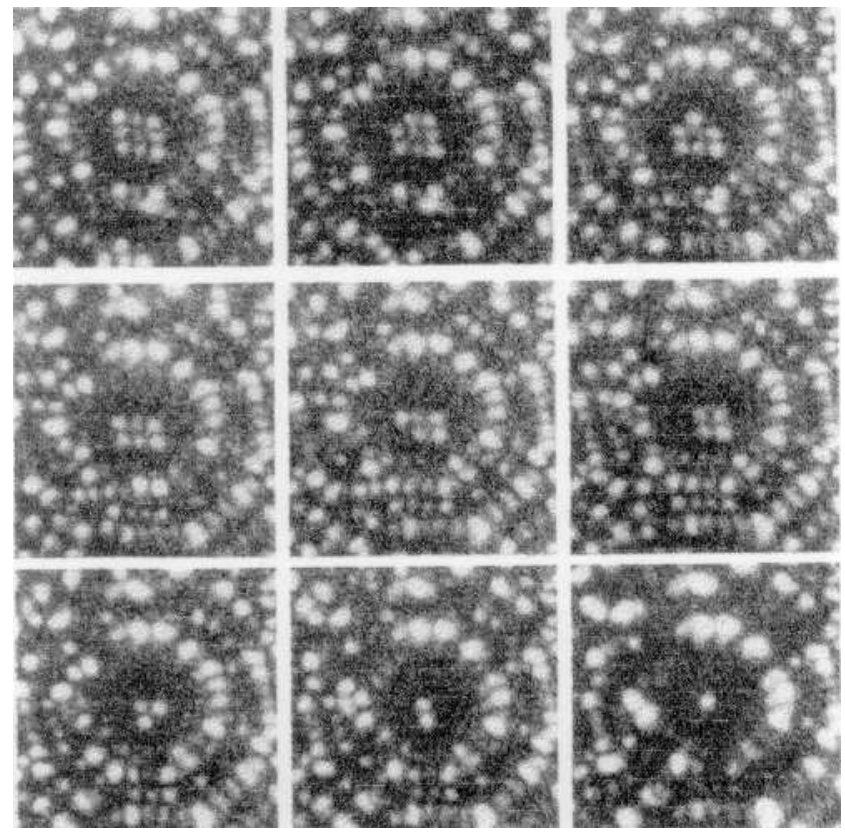

Figura 17. Sequiência de imagens obtidas com o FIM. O último plano atômico possui 9 átomos que são, individual e sucessivamente, removidos por evaporação induzida por campo. Trata-se de uma amostra inter-metálica de Níquel-Zircônio. (Foto gentilmente cedida por M. K. Miller - Oak Ridge National Laboratory, EUA).

Atualmente três técnicas de microscopia são capazes de fornecer resolução em escala atômica: Microscopia Iônica de Campo (Field Ion Microscopy), Microscopia Eletrônica de Alta Resolução (High Resolution Electron Microscopy HREM) e a Microscopia de Tunelamento e Varredura (Scanning Tunneling Microscopy - STM). A menção eventualmente feita de que é possível "ver" os átomos não é mais razão de surpresa, seja no meio científico ou mesmo no meio jornalístico especializado. A situação no entanto era bastante diferente 45-50 anos atrás. Os trabalhos de Müller e colaboradores representaram o primeiro grande passo para superar o que parecia até então impossível: os átomos seriam pequenos demais para serem de alguma forma individualmente identificados. Após as primeiras imagens com o FIM, foram necessários mais 25 anos para que imagens com resolução em escala atômica fossem fornecidas mediante HREM (em 1980), enquanto o STM conseguiu isto só em 1984. Os modernos equipamentos que utilizam, pelo 
menos em parte, a concepção básica do FIM são utilizados em pesquisas em várias áreas do conhecimento: metalurgia, reações catalíticas, determinação da estrutura de superfícies e mecanismos de adsorção e difusão em vários tipos de materiais [4]. A forma mais moderna destes equipamentos, o Atom-probe Field Ion Microscope, encontra-se em operação em vários centros de pesquisa dos países mais desenvolvidos. Um campo de pesquisa que o Brasil pode e deverá passar a utilizar.

\section{Referências}

[1] A. J. Melmed, Applied Surface Science, 94/95 (1996) 17.

[2] E. W. Müller, Z. Naturforsch. 11a. (1956) 88.

[3] E. W. Müller, J. Appl. Phys. 27 (1956) 474.

[4] D. P. Woodruff e T. A. Delchar, em: Modern Techiniques of Surface Science, Cambridge University Press, Cambridge, 1986.

\section{Vocabulário}

- Adsorção - Processo de fixação das moléculas de uma substância (o adsorvato) na superfície de uma outra substância (o adsorvente).

- Angstrom $(\AA)$ - Unidade de comprimento correspondente a $10^{-10}$ do metro, ou $0,1 \mathrm{~nm}$.

- Átomo - A menor quantidade de um elemento químico que pode existir como um ente estável, i. e., que mantém as propriedades químicas do elemento. Constitui assim a menor porção de um elemento químico que pode participar de uma reação química.

- Comprimento de Onda de de Broglie - Uma partícula com massa m, movendo-se com velocidade $\mathrm{v}$, pode, quando submetida a certas condições experimentais, apresentar um comportamento ondulatório, apresentando-se como uma onda de comprimento de onda $\lambda$ tal que $\lambda=\mathrm{h} / \mathrm{mv}$, onde $\mathrm{h}$ é a constante de Planck.

- Dessorção - É o processo inverso da adsorção, ou seja, é o mecanismo de separação de uma molécula de uma superfície à qual a molécula estava anteriormente ligada. O processo de dessorção pode ser provocado de diversas maneiras, como por exemplo pela incidência de radiação ou por aquecimento. A um processo deste tipo denomina-se de dessorção estimulada ou induzida.

- Dessorção por Campo (“Field Desorption”) - É o processo de dessorção estimulado pela ação de um campo externo, usualmente um campo elétrico. Reserva-se o uso desta expressão para o caso onde as moléculas que são liberadas são de natureza distinta daquelas que constituem o adsorvato.

- Elemento Químico - Substância que não pode ser decomposta, mediante os processos químicos ordinários, em outras substâncias mais simples, substância composta por átomos com a mesma carga nuclear.

- Evaporação por Campo (Field Evaporation) - É o processo de dessorção, estimulada pela ação de um campo externo, numa situação onde a natureza das moléculas, tanto do adsorvato quanto do adsorvente, é a mesma.

- Molécula - A menor quantidade de uma substância que pode existir em estado livre.

- Nanômetro (nm) - Unidade de comprimento que corresponde a $10^{-9}$ do metro, i. e., uma fração igual a 1/1 000000000 (1 bilionésimo do metro). Um nm corresponde assim a 10 Angstroms.

- Pressão - A pressão num certo ponto de um fluido, gás ou líquido, corresponde à força exercida por unidade de área num plano infinitesimal eventualmente colocado no ponto.

- A unidade SI, denominada de Pascal (Pa), corresponde à pressão que resulta da aplicação de uma força de intensidade igual a 1.0 Newton atuando de forma uniformemente distribuída numa área de 1,0 $\mathrm{m}^{2}$. Outras unidades são a pressão atmosférica, o mm de $\mathrm{Hg}$ e o Torr.

- 1,0 Torr $=133,322 \mathrm{~Pa}=1 / 760$ atmosferas

- 1,0 atmosfera $=760 \mathrm{~mm}$ de $\mathrm{Hg}$.

- Resolução ou Potência de Resolução - Em um telescópio ou em um microscópio, esta característica diz respeito à capacidade do equipamento em detectar como imagens separadas dois objetos próximos.

\section{Agradecimentos}

O autor reconhece o benefício de conversas e de correspondências estabelecidas, em momentos vários, com os Drs. Allan Melmed, Alfred Cerezo, David Kingham, George Smith e Richard Forbes. Ângela Lühning nos ajudou com textos em alemão enquanto Virgínia Lúcia Pimentel Souza, Hudson Cabral Sales de Souza e Von Braun Nascimento foram de grande valia na preparação dos desenhos. 